\title{
Low-Volume Leukapheresis in Non-Cytokine-Stimulated Donors for the Collection of Mononuclear Cells
}

\author{
Adamma Anyanwu $^{a}$ Nicole Sitzmann ${ }^{a}$ Svetlana Hetjens ${ }^{b}$ Harald Klüter ${ }^{a}$ Patrick Wuchter ${ }^{a}$ \\ ${ }^{a}$ Institute of Transfusion Medicine and Immunology, Medical Faculty Mannheim, Heidelberg University, \\ German Red Cross Blood Service Baden-Württemberg - Hessen, Mannheim, Germany; \\ ${ }^{b}$ Institute of Medical Statistics, Biomathematics and Informatics, Heidelberg University, Medical Faculty Mannheim, Mannheim, Germany
}

\section{Keywords}

Apheresis · MNC · Donors · Spectra Optia

\section{Summary}

Background: There is an increasing demand for products containing mononuclear cells (MNCs) for cellular immune therapy. Hence, leukapheresis is increasingly performed in healthy volunteer donors. Methods: We evaluated 147 low-volume leukapheresis procedures from 77 healthy non-cytokine-stimulated donors. Complete blood counts (CBCs) of the donors were measured before and directly after the procedures as well as from the MNC products. Follow-up CBCs were collected from donors within 21 days. Results: The product hematocrit within a range from 1.2 to $6.0 \%$ did not correlate with the collection efficiency of any cell population or the granulocyte and platelet yield. There was a strong correlation between the $\mathrm{CBC}$ values before leukapheresis and the cell yield of lymphocytes and monocytes as well as a perfect negative correlation between cell recruitment and cell loss in all cell populations. Furthermore, we observed a significant decrease in the $\mathrm{CBC}$ values in all cell populations directly after leukapheresis, which recovered within a mean of 16.1 days ( $S D \pm 2.1$ days) and even showed a significant increase in granulocytes and platelets. Conclusion: Low-volume leukapheresis is feasible for the collection of MNCs in which the product hematocrit is negligible for the collection efficiency, cell yield, or contamination of residual cells under operational settings recommended by the manufacturer. Our data suggests that cell recruitment is regulated by the number of cells removed, which may also be the stimulus to induce granulo- and thrombopoiesis within the first days after leukapheresis.

(C) 2018 S. Karger GmbH, Freiburg

\section{Introduction}

The demand for cellular products containing mononuclear cells (MNCs) for dendritic cell culture or lymphocyte-derived immune therapies in preclinical or clinical studies has risen. The blood transfusion services of Baden-Württemberg-Hessen and Nord-Ost performed 124 leukapheresis in healthy donors in 2007 for the use as a donor lymphocyte infusion (DLI) or for research purpose. Ten years later, the number of leukapheresis in healthy donors has nearly tripled up to 336 leukapheresis sessions per year. MNCs can be isolated from whole blood-derived buffy coats, but if high numbers of MNCs are required, leukapheresis is the method of choice for MNC collection [1]. This led to the inclusion of leukapheresis procedures in the German guidelines for hemotherapy 2017 [2]. Recommendations were made for the frequency and interval as well as for the performance of leukapheresis donations for both patients (autologous collection) and allogeneic donors. Previous studies demonstrated that leukapheresis with a number of different apheresis devices is a feasible method to obtain a sufficient amount of MNCs either for dendritic cell culture, donor lymphocyte infusions (DLI), or extracorporeal photopheresis (ECP) with a low number of adverse events [3-5]. Depending on the amount of MNCs needed for the experimental purpose or therapeutic approach, the blood volume that needs to be processed, the duration of the procedure, and the product volume can vary.

Since only few studies of the individual apheresis devices and operating programs have been published, comparison of the available data regarding collection efficiency and donor response is difficult. The continuous mononuclear cell program (CMNC) of the Spectra Optia system by Terumo BCT (Zaventem, Belgium) was evaluated in a number of studies which aimed to collect peripheral blood stem cells (PBSCs) in allogeneic or autologous donors after granulocyte-colony stimulating factor (G-SCF) mobilization [6-9]. However, there is hardly any published data about MNC collection with this program in non-stimulated healthy donors. The first

\section{KARGER}

() 2018 S. Karger GmbH, Freiburg

Fax +497614520714 
study which compared the earlier introduced discontinuous MNC program on the Spectra Optia to the CMNC program for MNC collection indicated a higher efficiency of the CMNC program, resulting in a smaller product volume and a shorter procedure time by comparable MNC yield [10]. Notwithstanding the above, the CMNC program remains easier to monitor and can be controlled more precisely than the MNC program. In addition, previous studies focused mainly on the differences in leukapheresis procedures and their performance $[11,12]$. Only a few publications included the short-term impact of the procedure on the donor $[5,13]$.

In this study we investigated low-volume leukapheresis with the Spectra Optia using the CMNC program in non-cytokine stimulated donors. The major aims were to evaluate the feasibility of the program for $\mathrm{MNC}$ collection and the impact of the leukapheresis on the complete blood count $(\mathrm{CBC})$ values of the donors.

\section{Material and Methods}

\section{Study Design and Donor Selection}

We performed a retrospective, single-center analysis of 147 leukapheresis procedures for the collection of MNCs at our institute from February 2015 until August 2017. For the main study, which investigated T cells and their receptors out of leukapheresis products from healthy donors, only donors were chosen with apheresis experience and specific human leukocyte antigen genotypes according to the requirements of the study. The inclusion criteria regarding the donor selection and leukapheresis procedure were as follows: i) total processed blood volume $(\mathrm{TPV}) \leq 51$ or ii) TPV (fold) $\leq 1.04$, or iii) product volume $\leq 100$ $\mathrm{ml}$. In accordance with the German guidelines, all donors were allowed to perform up to 6 leukaphereses within 12 months, the interval between 2 consecutive leukaphereses being at least 4 weeks. After each procedure, an interval of at least 14 days had to be maintained before other apheresis or blood donations could follow. Thus, we included more than one leukapheresis procedure per donor in the observation period. All donors met the German guidelines for blood transfusions and gave written informed consent prior to leukapheresis. The study was approved by the Ethics Committee of the Medical Faculty Mannheim, Heidelberg University.

\section{Leukapheresis Procedures}

All leukapheresis procedures were performed via peripheral vein access using the CMNC program (software version 11.3) of the Spectra Optia system (Terumo BCT) according to the instructions of the manufacturer and default settings described previously [10]. Unlike Punzel et al. [10] the packing factor was unaltered and used at its default setting of 4.5. For anticoagulation the acidcitrate-dextrose formula A (ACD-A) (Terumo BCT) was used without additional heparin. The flow rate was set at $0.8 \mathrm{ml} / \mathrm{min} / \mathrm{LTBV}$ with an anticoagulation:inlet ratio of 1:12. Depending on the inlet flow rate during the leukapheresis, which could vary between 40 and $70 \mathrm{ml} / \mathrm{min}$, the anticoagulation flow rate varied accordingly between 0.7 and $1.1 \mathrm{ml} / \mathrm{min} / \mathrm{LTBV}$. The collection flow rate was set at $1 \mathrm{ml} / \mathrm{min}$. Monitoring of the procedure was achieved by observing the apparent hematocrit (Hct) in the collection line with the colorgram provided by the manufacturer to the level of 3\%. According to Jestice et al. [14] and in agreement with the manufacturers' recommendations, $3 \%$ is regarded to be the optimal Hct concentration for the collection of white blood cells (WBCs).

Blood Sampling and Analysis

Blood samples $(4 \mathrm{ml})$ were collected into anticoagulated tubes containing ethylenediamine tetra-acetic acid (EDTA) from all donors before and immediately after leukapheresis. An additional blood sample was obtained from all donors, who returned within 21 days after their initial leukapheresis for any other kind of apheresis donation. In this regard, the donors were not actively invited to return within 21 days for another apheresis or complete blood count after their initial leukapheresis had taken place. Those CBCs were analyzed retrospectively from all donors, who happened to return to the institute within 21 day by chance. From each MNC product, a sample was withdrawn aseptically. A CBC was performed for each sample using an automated hematology analyzer (Cell-Dyn 3700 or Cell-Dyn Ruby; Abbott Laboratories, Chicago, IL, USA). Both analyzers use an optic laser system which results in a multiple scatterplot analysis to differentiate the WBCs.

\section{Formulas}

The following formulas were used to evaluate the leukapheresis procedure:

Cell yield:

Cell yield $=$ product cell concentration $\times$ product volume

Collection efficiency:

$\mathrm{CE} 2 \%=$ cell yield $\times 100 /($ cell concentration pre-apheresis $\times \mathrm{TPV})$

Total circulating cells pre-apheresis:

TC pre-apheresis $=$ Cell concentration pre-apheresis $\times$ TBV pre-apheresis

Total circulating cells post-apheresis:

TC post-apheresis $=$ Cell concentration post-apheresis $\times$ TBV post-apheresis

The total blood volume (TBV) post-apheresis was calculated by adding the TBV pre-apheresis, which was given by the Spectra Optia system after entering sex, body weight, and body height into the donors' data sheet of the device, and the subtotal volume of the fluid balance including blood return at the end of the procedure $(\mathrm{TBV}$ post-apheresis $=\mathrm{TBV}$ pre-apheresis + subtotal volume including blood return). Here, we took into account that the donor has a positive fluid balance at the end of each procedure.

Cell loss:

Cell loss $\%=($ TC pre-apheresis - TC post-apheresis $) \times 100 /$ TC pre-apheresis

Cell recruitment:

$\mathrm{RF}=\mathrm{TC}$ post-apheresis + cell yield $/ \mathrm{TC}$ pre-apheresis

Statistical Analysis

All statistical calculations were performed using SAS software, release 9.3 (SAS Institute Inc., Cary, NC, USA). Quantitative approximately normally distributed parameters are presented as mean values and standard deviations; for skewed data, median and range are given. Qualitative data are described by their absolute and relative frequencies. Correlations between two variables were ascertained with the Pearson's $r$ test and regarded as a moderate correlation when $r$ was greater than 0.4 and as a strong correlation when $r$ was greater than 0.6. The calculation of the coefficient of determination $\left(\mathrm{R}^{2}\right)$ was used to explain the goodness of fit of the linear model and was regarded as relevant if $\mathrm{R}^{2}$ was greater 0.65 .

For approximately normally distributed data, two-sample t-tests have been used. Paired t-tests were used to compare the measurements. Statistical significance has been assumed for $\mathrm{p}$ values less than 0.05 .

Box plots and correlation graphics were generated with MS Excel 2010 (Microsoft, Redmond; WA, USA).

\section{Results}

\section{Donors and Leukapheresis Safety}

Between February 2015 and August 201777 healthy non-cytokine-stimulated donors (70 male and 7 female) performed a total 
Table 1. Leukapheresis variables and product characteristics

\begin{tabular}{llc}
\hline Variable & N & Mean \pm SD \\
\hline TPV, 1 & 147 & $4.75 .0 \pm 0.67$ \\
TPV, fold & 147 & $0.86 \pm 0.10$ \\
Product volume, ml & 147 & $93.1 \pm 6.82$ \\
Hct product, \% & 145 & $2.75 \pm 0.96$ \\
WBC yield $\times 10^{9}$ & 147 & $7.29 \pm 2.06$ \\
Granulocyte yield $\times 10^{9}$ & 147 & $0.36 \pm 0.42$ \\
Lymphocyte yield $\times 10^{9}$ & 147 & $5.21 \pm 1.65$ \\
Monocyte yield $\times 10^{9}$ & 147 & $1.54 \pm 0.56$ \\
RBC yield $\times 10^{9}$ & 146 & $29.9 \pm 11.9$ \\
PLT yield $\times 10^{9}$ & 147 & $225.7 \pm 78.7$ \\
CE2 WBC & 147 & $24.2 \pm 4.61$ \\
CE2 Granulocytes & 146 & $2.08 \pm 1.80$ \\
CE2 Lymphocytes & 146 & $61.6 \pm 9.60$ \\
CE2 Monocytes & 146 & $53.9 \pm 11.4$ \\
CE2 RBCs & 146 & $0.13 \pm 0.05$ \\
CE2 PLTs & 147 & $21.7 \pm 5.58$ \\
\hline TPV $=$ Total processed blood volume; Hct $=$ hematocrit; WBC $=$ white blood \\
cells; RBCs = red blood cells; PLTs $=$ platelets; CE2 = calculated collection \\
efficiency. & & \\
\hline & & \\
\hline
\end{tabular}

of 147 leukapheresis procedures. 44 donors donated once, 14 donors twice, and 19 donors $\geq 3$ times during this period. They had a mean age of $36.7 \pm 11.7$ years with a mean body weight of $86.4 \pm$ $14.7 \mathrm{~kg}$, a mean body mass index of $26.8 \pm 4.09 \mathrm{~m}^{2} / \mathrm{kg}$ and a mean blood volume of $5.52 \pm 0.66 \mathrm{l}$. Due to the shortness of the leukapheresis, all procedures were tolerated well. Only mild adverse events in terms of citrate reactions with mild symptoms of paresthesia were reported sporadically. Upon report, the donor received oral calcium, which led to quick resolution of the symptoms. No severe adverse events were reported.

\section{Collection Results}

In 147 leukapheresis procedures, we processed a mean blood volume of $4.75 \pm 0.67 \mathrm{l}$ and obtained a mean product volume of $93.1 \pm 6.82 \mathrm{ml}$ with a mean product Hct of $2.75 \pm 0.96 \%$. The cell yield and the CE2 values are summarized in table 1. Generally, all products had a mean percentage of $92.6 \pm 3.77 \%$ MNCs out of all WBCs.

To investigate the influence of the product Hct on the CE2 values and the product cell yield of each cell population, the 147 leukapheresis procedures were divided into two groups. The median value of the product Hct (2.6\%) served as threshold. All leukapheresis procedures with a product Hct of $<2.6 \%$ were included in group 1, whereas all others were included in group 2. Donor characteristics of each group as well as their $\mathrm{CBC}$ values before leukapheresis are presented in table 2 . The donors were equally distributed to both groups with comparable characteristics. The CBC values before leukapheresis showed no significant differences between both groups. In agreement with the difference in the product Hct in both groups, only the CE2 value and the cell yield of the red blood cells (RBC) in group 1 was significantly lower than in group
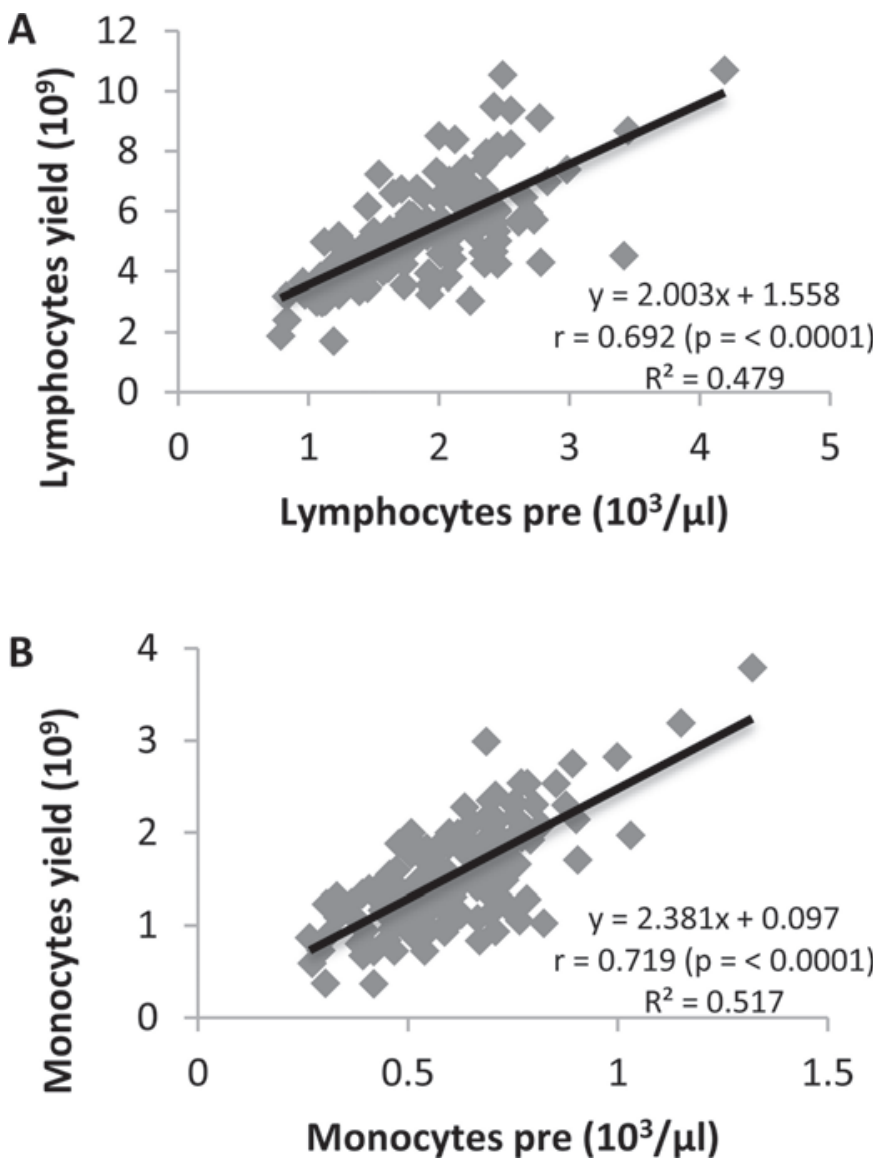

Fig. 1. Correlation between complete blood count (CBC) values before leukapheresis and corresponding collection result values. Correlation between lymphocyte values before leukapheresis (Lymphocytes pre) and the lymphocyte yield in the product $(\mathbf{A})$. Correlation between monocyte values before leukapheresis (Monocytes pre) and the monocyte yield in the product (B).

$2\left(\mathrm{p}_{\mathrm{CE} 2 \mathrm{RBC}}<0.0001 ; \mathrm{p}_{\mathrm{RBC}}\right.$ yield $\left.<0.0001\right)$. In all other cell populations, no significant difference in the CE2 values or the cell yield was observed between the two groups (table 2). Moreover, concerning product contamination with granulocytes and platelets (PLTs) the product Hct did not correlate with the granulocyte $\left(\mathrm{r}_{\mathrm{Hct} / \text { Granu yield }}=0.010\right)$ or PLT yield $\left(\mathrm{r}_{\mathrm{Hct} / \text { PLT yield }}=0.077\right)$ in general correlation analysis.

Given that the product Hct had no influence on the CE2 values, we investigated the correlation between the $\mathrm{CBC}$ values before leukapheresis and the cell yield (fig. 1). We found significant moderate to strong correlations between the $\mathrm{CBC}$ values before leukapheresis and the corresponding cell yield for WBCs $(\mathrm{r}=0.527$; $\mathrm{p}<$ $0.0001)$, lymphocytes $(r=0.692 ; \mathrm{p}<0.0001)$, monocytes $(\mathrm{r}=0.719$; $\mathrm{p}<0.0001)$, and PLTs $(\mathrm{r}=0.582 ; \mathrm{p}<0.0001)$. Only the corresponding correlations for granulocytes $\left(\mathrm{r}_{\text {Granu pre/yield }}=0.373 ; \mathrm{p}<0.0001\right)$ and $\mathrm{RBCs}\left(\mathrm{r}_{\mathrm{RBC}}\right.$ pre/yield $\left.=-0.092 ; \mathrm{p}=0.2666\right)$ remained weak. However, the coefficient of determination values $\left(\mathrm{R}^{2}\right)$ of the other cell populations express a weak explanation for these relationships $\left(\mathrm{R}^{2}{ }_{\mathrm{WBC} \text { pre/yield }}=0.278 ; \mathrm{R}_{\text {Lymph pre/yield }}^{2}=0.479 ; \mathrm{R}^{2}\right.$ Mono pre/yield $=$ $0.517 ; \mathrm{R}^{2}$ PLT pre/yield $=0.339$ ). Searching for other variables which influence the correlation between $\mathrm{CBC}$ values before leukapheresis 
Table 2. Donor characteristics and collection efficiency in dependence of the product hematocrit

\begin{tabular}{|c|c|c|c|c|c|}
\hline \multirow[b]{2}{*}{ Variable } & \multicolumn{2}{|c|}{ Group 1} & \multicolumn{2}{|c|}{ Group 2} & \multirow[t]{2}{*}{$\mathrm{p}$ value } \\
\hline & $\mathrm{N}$ & mean $\pm S D$ & $\mathrm{~N}$ & mean $\pm \mathrm{SD}$ & \\
\hline \multicolumn{6}{|l|}{ Donor characteristics } \\
\hline Donors & 51 & & 48 & & \\
\hline $\operatorname{Sex} M / F$ & $47 / 4$ & & $44 / 4$ & & \\
\hline Age, years & & $36.8 \pm 11.6$ & & $37.6 \pm 11.6$ & \\
\hline Body weight, kg & & $87.2 \pm 15.0$ & & $86.9 \pm 16.0$ & \\
\hline Body mass index, $\mathrm{kg} / \mathrm{m}^{2}$ & & $26.8 \pm 4.21$ & & $27.0 \pm 4.35$ & \\
\hline TBV, 1 & & $5.55 \pm 0.68$ & & $5.51 \pm 0.63$ & \\
\hline \multicolumn{6}{|c|}{ CBC values before leukapheresis } \\
\hline WBC pre $\times 10^{3} / \mu \mathrm{l}$ & 69 & $6.42 \pm 1.55$ & 76 & $6.43 \pm 1.24$ & NS \\
\hline Granulocytes pre $\times 10^{3} / \mu \mathrm{l}$ & 68 & $3.72 \pm 1.28$ & 76 & $3.63 \pm 0.9$ & NS \\
\hline Lymphocytes pre $\times 10^{3} / \mu \mathrm{l}$ & 68 & $1.78 \pm 0.53$ & 76 & $1.85 \pm 0.61$ & NS \\
\hline Monocytes pre $\times 10^{3} / \mu \mathrm{l}$ & 68 & $0.59 \pm 0.17$ & 76 & $0.61 \pm 0.16$ & NS \\
\hline RBCs pre $\times 10^{6} / \mu \mathrm{l}$ & 69 & $5.04 \pm 0.40$ & 76 & $5.01 \pm 0.37$ & NS \\
\hline Hct pre, $\%$ & 21 & $43.4 \pm 3.56$ & 24 & $44.2 \pm 3.27$ & NS \\
\hline PLTs pre $\times 10^{3} / \mu \mathrm{l}$ & 69 & $219.6 \pm 49.2$ & 76 & $222.9 \pm 44.2$ & NS \\
\hline \multicolumn{6}{|l|}{ Product characteristics } \\
\hline Hct product, \% & 69 & $2.01 \pm 0.32$ & 76 & $3.43 \pm 0.85$ & $<0.0001$ \\
\hline WBC yield $\times 10^{9}$ & 69 & $7.30 \pm 2.15$ & 76 & $7.31 \pm 1.99$ & NS \\
\hline Granulocyte yield $\times 10^{9}$ & 69 & $0.40 \pm 0.56$ & 76 & $0.34 \pm 0.26$ & NS \\
\hline Lymphocyte yield $\times 10^{9}$ & 69 & $5.24 \pm 1.70$ & 76 & $5.21 \pm 1.63$ & NS \\
\hline Monocyte yield $\times 10^{9}$ & 69 & $1.52 \pm 0.58$ & 76 & $1.57 \pm 0.54$ & NS \\
\hline RBC yield $\times 10^{9}$ & 69 & $22.1 \pm 5.10$ & 76 & $37.2 \pm 11.6$ & $<0.0001$ \\
\hline PLT yield $\times 10^{9}$ & 69 & $225.3 \pm 82.2$ & 76 & $228.5 \pm 75.2$ & NS \\
\hline \multicolumn{6}{|l|}{ Collection efficiency } \\
\hline CE2 WBC & 69 & $24.1 \pm 4.50$ & 76 & $24.4 \pm 4.76$ & NS \\
\hline CE2 Granulocytes & 68 & $2.18 \pm 2.20$ & 76 & $1.99 \pm 1.36$ & NS \\
\hline CE2 Lymphocytes & 68 & $62.4 \pm 9.27$ & 76 & $61.3 \pm 9.77$ & NS \\
\hline CE2 Monocytes & 68 & $53.4 \pm 10.3$ & 76 & $54.6 \pm 12.1$ & NS \\
\hline CE2 RBCs & 69 & $0.09 \pm 0.03$ & 76 & $0.16 \pm 0.05$ & $<0.0001$ \\
\hline CE2 PLTs & 69 & $21.5 \pm 5.66$ & 76 & $21.9 \pm 5.52$ & NS \\
\hline
\end{tabular}

Table 3. Cell count of donors before and directly after leukapheresis

\begin{tabular}{|c|c|c|c|c|c|}
\hline \multirow[t]{3}{*}{ Variable } & \multicolumn{4}{|c|}{ Cell count } & \multirow[t]{3}{*}{$\mathrm{p}$ value } \\
\hline & \multicolumn{2}{|l|}{ pre } & \multicolumn{2}{|l|}{ post } & \\
\hline & $\mathrm{N}$ & mean $\pm \mathrm{SD}$ & $\mathrm{N}$ & mean $\pm \mathrm{SD}$ & \\
\hline WBCs $\times 10^{3} / \mu \mathrm{l}$ & 147 & $6.42 \pm 1.38$ & 144 & $5.55 \pm 1.22$ & $<0.0001$ \\
\hline Granulocytes $\times 10^{3} / \mu \mathrm{l}$ & 146 & $3.66 \pm 1.09$ & 103 & $3.45 \pm 1.05$ & 0.0008 \\
\hline Lymphocytes $\times 10^{3} / \mu \mathrm{l}$ & 146 & $1.82 \pm 0.57$ & 103 & $1.34 \pm 0.39$ & $<0.0001$ \\
\hline Monocytes $\times 10^{3} / \mu \mathrm{l}$ & 146 & $0.60 \pm 0.17$ & 103 & $0.44 \pm 0.10$ & $<0.0001$ \\
\hline $\mathrm{RBCs} \times 10^{6} / \mu \mathrm{l}$ & 147 & $5.02 \pm 0.39$ & 103 & $4.73 \pm 0.42$ & $<0.0001$ \\
\hline Hct, \% & 141 & $44.3 \pm 2.84$ & 144 & $41.5 \pm 2.99$ & $<0.0001$ \\
\hline PLTs $\times 10^{3} / \mu \mathrm{l}$ & 147 & $220.7 \pm 46.5$ & 143 & $195.6 \pm 40.7$ & $<0.0001$ \\
\hline
\end{tabular}

and the cell yield in the product, the TPV was found to be a significant dependent variable for WBCs, lymphocytes, monocytes, and PLTs $(\mathrm{p}<0.0001)$. Taking the TPV into account, only the $\mathrm{R}^{2}$ values for the correlation between the $\mathrm{CBC}$ values before leukapheresis and the cell yield for lymphocytes $\left(\mathrm{R}^{2}\right.$ Lymph pre/yield $\left.(\mathrm{TPV})=0.749\right)$ and monocytes $\left(\mathrm{R}^{2}\right.$ Mono pre/yield (TPV) $\left.=0.694\right)$ were increased to a relevant measure. 
Donor Response to Leukapheresis and the Role of Donors' Fluid Balance

Comparing the $\mathrm{CBC}$ before and immediately after leukapheresis, a significant decrease in the $\mathrm{CBC}$ values of all cell populations after leukapheresis was observed (table 3).

We analyzed the cell loss in 34 leukapheresis procedures. But, differing in the initial calculation formulas used by Strasser et al. [15], we took into account that after blood return the donors have a positive fluid balance at the end of each procedure, when the blood samples are drawn. The modified formulas are given in the 'Material and Methods' section. In this respect, the mean cell loss
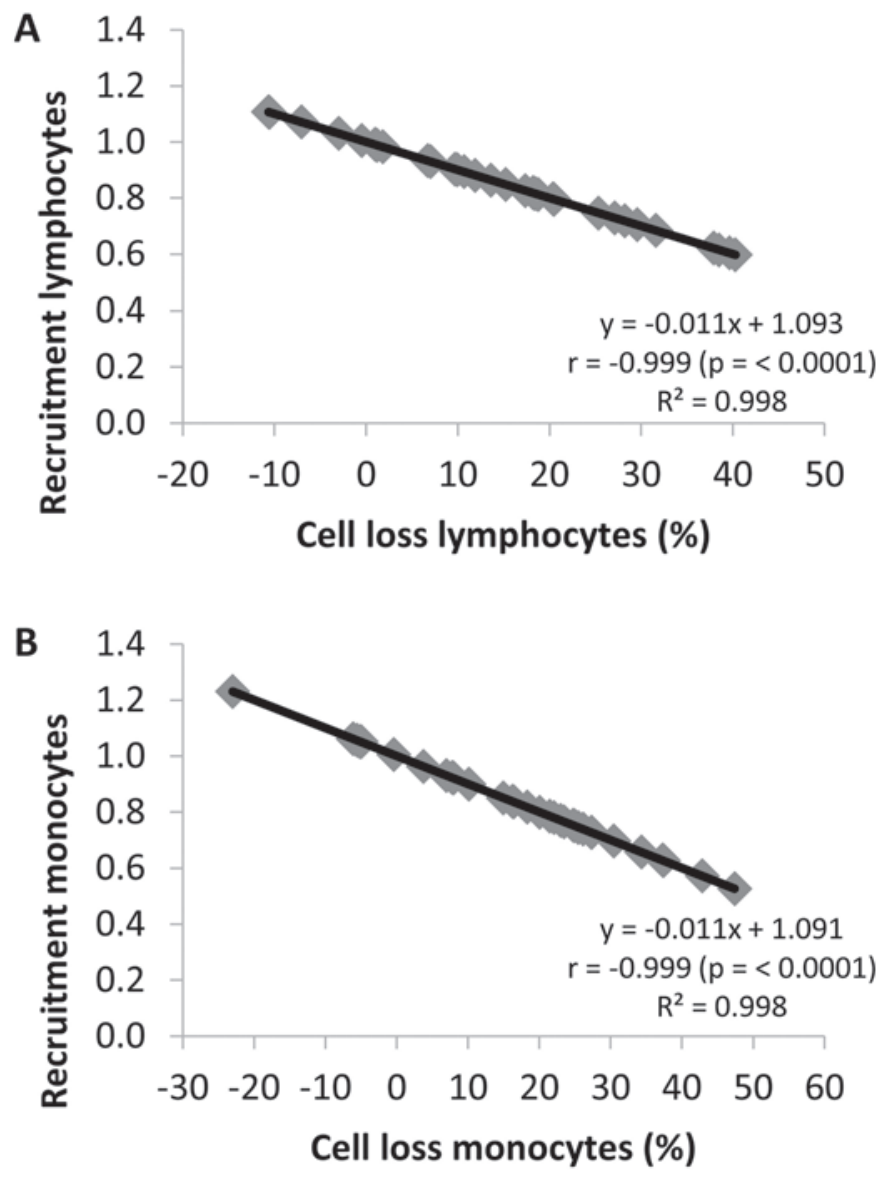

Fig. 2. Correlation between cell loss and cell recruitment. Correlation be tween cell loss and cell recruitment of lymphocytes $(\mathbf{A})$ and of monocytes $(\mathbf{B})$. was noted to be highest for lymphocytes and monocytes (table 4). The ranges of the cell loss with its negative minimum values indicate that against the expectations some donors had higher $\mathrm{CBC}$ values after the leukapheresis than before. However, the highest percentage of negative cell loss values out of all measured values were found for the RBCs (76.5\%), granulocytes (63.6\%), and PLTs (47.1\%) (table 4).

To investigate if these findings could partially be explained by RF, we modified the initial formula described by Knudsen et al. [16] in a similar manner to the formula for cell loss and considered the positive fluid balance of the donor at the end of the leukapheresis. The mean values and the ranges of the RF are demonstrated in table 4. An RF value of one (or lower) means that no cell recruitment occurred during the collecting process, whereas values greater than one are an indication for cell mobilization. Given that the mean values are all close to one or below, it seems that in general no cell recruitment occurred. However, when looking at the correlation between the RF values and the cell loss, we found a perfect negative correlation for all cell populations between both variables: the higher the RF the lesser the cell loss (table 4, fig. 2).

In search for influencing variables, both the RF and the cell loss of lymphocytes showed a strongly positive and negative correlation with the corresponding CE2 values respectively $\left(\mathrm{r}_{\mathrm{Lymph} \mathrm{RF} / \mathrm{CE} 2}=\right.$ 0.779; $\mathrm{r}_{\text {Lymph Cell loss/CE2 }}=-0.779 ; \mathrm{p}<0.0001$ ) (fig. 3). For all other cell populations we could not detect a correlation between the RF or the cell loss and the corresponding CE2 values $\left(\mathrm{r}_{\mathrm{WBC} \text { RF/CE2 }}=\right.$ $-0.017 ; \mathrm{r}_{\mathrm{WBC} \text { Cell loss } / \mathrm{CE} 2}=0.018 ; \mathrm{r}_{\text {Granu RF/CE2 }}=-0.153 ; \mathrm{r}_{\text {Granu Cell loss } /}$ $\mathrm{CE} 2=0.153 ; \mathrm{r}_{\mathrm{Mono} R} / \mathrm{CE} 2=-0.012 ; \mathrm{r}_{\text {Mono Cell loss } / \mathrm{CE} 2}=0.012 ; \mathrm{r}_{\mathrm{RBC} \mathrm{RF} /}$ $\mathrm{CE} 2=-0.009 ; \mathrm{r}_{\mathrm{RBC} \text { Cell loss } / \mathrm{CE} 2}=0.020 ; \mathrm{r}_{\mathrm{PLT} \text { RF } / \mathrm{CE} 2}=0.054 ; \mathrm{r}_{\mathrm{PLT} \text { Cell loss } /}$ $\mathrm{CE} 2=-0.054)$.

To evaluate the impact of cell loss and recruitment on the donors' $\mathrm{CBC}$ values, we examined the normalization of the mean decreases in all cell populations. For this purpose, we collected CBCs of all donors who returned to the institute within 21 days after their initial leukapheresis. In the observation period between February 2015 and August 2017, 28 donors out of 77 (36\%) returned to the institute a total of 43 times within 21 days after the initial 147 leukapheresis procedures for apheresis donation. These donors had a mean age of $37.2 \pm 11.7$ years with a mean body weight of $89.5 \pm 16.5 \mathrm{~kg}$, a mean body mass index of $27.9 \pm 4.98 \mathrm{~kg} / \mathrm{m}^{2}$, and a mean blood volume of $5.60 \pm 0.64 \mathrm{l}$. Within a mean of $16.1 \pm 2.1$

Table 4. Cell recruitment and cell loss during leukapheresis

\begin{tabular}{|c|c|c|c|c|c|c|c|}
\hline \multirow[t]{2}{*}{ Variable } & \multirow[t]{2}{*}{$\mathrm{N}$} & \multirow{2}{*}{$\frac{\text { Pre }}{\text { mean } \pm \mathrm{SD}}$} & \multirow{2}{*}{$\begin{array}{c}\text { Post } \\
\text { mean } \pm \mathrm{SD}\end{array}$} & \multirow{2}{*}{$\begin{array}{l}\text { Recruitment } \\
\text { mean (range) }\end{array}$} & \multicolumn{2}{|l|}{ Cell loss (\%) } & \multirow[t]{2}{*}{$\mathrm{r}$} \\
\hline & & & & & mean (range) & NV & \\
\hline TBV, 1 & 34 & $5.42 \pm 0.76$ & $5.91 \pm 0.80$ & & & & \\
\hline $\mathrm{WBCs} \times 10^{3} / \mu \mathrm{l}$ & 34 & $6.44 \pm 1.61$ & $5.67 \pm 1.40$ & $0.96(0.84-1.27)$ & $3.72(-26.7$ to 15.9$)$ & 23.5 & -0.999 \\
\hline Granulocytes $\times 10^{3} / \mu \mathrm{l}$ & 33 & $3.73 \pm 1.45$ & $3.61 \pm 1.30$ & $1.06(0.83-1.48)$ & $-6.00(-48.5$ to 17.3$)$ & 63.6 & -0.999 \\
\hline Lymphocytes $\times 10^{3} / \mu \mathrm{l}$ & 33 & $1.82 \pm 0.52$ & $1.39 \pm 0.40$ & $0.84(0.60-1.11)$ & $15.7(-10.6$ to 40.3$)$ & 15.2 & -0.999 \\
\hline Monocytes $\times 10^{3} / \mu \mathrm{l}$ & 33 & $0.61 \pm 0.13$ & $0.45 \pm 0.10$ & $0.83(0.53-1.23)$ & $17.4(-23.0$ to 47.4$)$ & 18.2 & -0.999 \\
\hline $\mathrm{RBCs} \times 10^{6} / \mu \mathrm{l}$ & 34 & $4.97 \pm 0.47$ & $4.69 \pm 0.46$ & $1.03(0.94-1.09)$ & $-2.81(-9.25$ to 5.68$)$ & 76.5 & -0.999 \\
\hline PLTs $\times 10^{3} / \mu \mathrm{l}$ & 34 & $216.6 \pm 41.0$ & $195.2 \pm 48.3$ & $0.98(0.67-1.26)$ & $1.99(-25.9$ to 33.1$)$ & 47.1 & -0.999 \\
\hline
\end{tabular}


days, all cell counts were either back to initial values before leukapheresis or even showed significant increase in granulocytes and PLTs (table 5, fig. 4).

\section{Discussion}

This retrospective study investigated 147 low-volume leukapheresis procedures performed with the CMNC program of the Spectra Optia. The two major aims were to analyze the perfor-
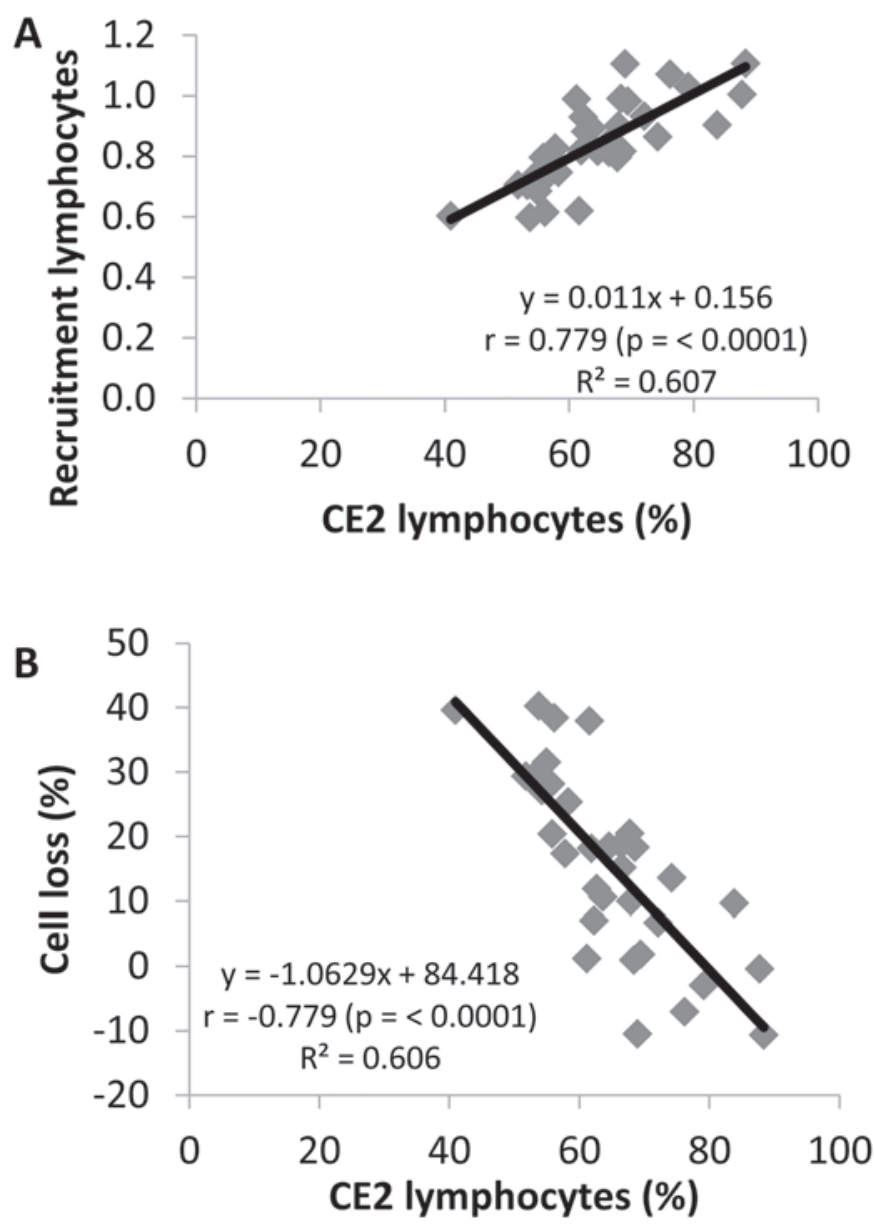

Fig. 3. Correlation between collection efficiency (CE2) of lymphocytes and donor response values. Correlation between calculated CE2 values (CE2 lymphocytes) and the cell recruitment (A) and the cell loss (B). mance of the procedure and to evaluate the impact of the leukapheresis on the CBC values of the donors.

Regarding the performance of the procedure, we could demonstrate a high-purity MNC yield with low contamination by granulocytes and PLTs. These findings are in agreement with the results of Schulz et al. [5]. Since we used the colorgram to monitor the collection line up to a Hct of $3 \%$, the general RBC contamination was as expected low and played a minor role in our study design. At the same time, the product Hct within a range from 1.2 to $6.0 \%$ had no influence on the CE2 values and the cell yield of any cell population or on the contamination with residual cells. In contrast to our findings, Strasser et al. [12], who had compared the collection result of leukapheresis with high-component Hct to procedures with low-component Hct, found significantly higher CD14+ cell yields with a simultaneous higher collection efficiency of MNCs in components with higher Hct. The WBC yield and the PLT contamination had also increased in those components, but without reaching significance. The diverse results may be due to two major factors. First, their leukapheresis procedures were performed with two different separation factors and centrifuge velocities. The yield of both procedures was assorted in one subset. This could explain why the group observed a higher PLT contamination in the subset with the higher component Hct. Second, the component Hct range of the subsets built (Cobe Spectra: $2.4-4.8 \%$ vs. $5.0-17.0 \%)$ was considerably higher than in our study $(1.2-2.5 \%$ vs. 2.6-6.0\%). Since it is advantageous to keep the residual cell contamination low in MNC collection, monitoring the Hct in the collection line to a level of 3\% is more contemporary and in agreement with the findings of Jestice et al. [14] and the manufacturers' recommendation for the Spectra Optia.

Furthermore, we could demonstrate that the $\mathrm{CBC}$ values before leukapheresis of all cell populations correlated significantly with their corresponding cell yield in the product. In correspondence with these results, Svensson et al. [17] found a strong correlation between the concentrations of monocytes and lymphocytes in the blood pre-apheresis and the number of monocytes and lymphocytes collected. In contrast, Punzel et al. [10] detected only a weak correlation between the $\mathrm{CD} 3+$ pre-apheresis values and the $\mathrm{CD} 3+$ cell yield in the product. Steininger et al. [11] could show a significant correlation between the pre-apheresis cell count and the correspondent product cell yield for CD14+ but not for CD3+ cells. Taken together, there seem to be further variables, which influence
Table 5. Cell count of donors before and $\leq 21$ days after leukapheresis

\begin{tabular}{|c|c|c|c|c|c|}
\hline \multirow[t]{2}{*}{ Variable } & \multicolumn{2}{|c|}{ Cell count pre } & \multicolumn{2}{|c|}{ Cell count post $\leq 21$ days } & \multirow[t]{2}{*}{$\mathrm{p}$ value } \\
\hline & $\mathrm{N}$ & mean $\pm S D$ & $\mathrm{~N}$ & mean $\pm S D$ & \\
\hline $\mathrm{WBC} \times 10^{3} / \mu \mathrm{l}$ & 43 & $6.64 \pm 1.62$ & 43 & $7.19 \pm 1.45$ & 0.0091 \\
\hline Granulocytes $\times 10^{3} / \mu \mathrm{l}$ & 40 & $3.90 \pm 1.51$ & 41 & $4.34 \pm 1.29$ & 0.0406 \\
\hline Lymphocytes $\times 10^{3} / \mu \mathrm{l}$ & 40 & $1.81 \pm 0.45$ & 41 & $1.91 \pm 0.40$ & NS \\
\hline Monocytes $\times 10^{3} / \mu \mathrm{l}$ & 40 & $0.62 \pm 0.15$ & 41 & $0.62 \pm 0.18$ & NS \\
\hline $\mathrm{RBCs} \times 10^{6} / \mu \mathrm{l}$ & 43 & $5.05 \pm 0.35$ & 43 & $5.05 \pm 0.30$ & NS \\
\hline Hct, \% & 41 & $44.3 \pm 2.81$ & 41 & $44.4 \pm 2.40$ & NS \\
\hline PLTs $\times 10^{3} / \mu \mathrm{l}$ & 43 & $229.2 \pm 49.9$ & 43 & $251.7 \pm 47.6$ & 0.0003 \\
\hline
\end{tabular}

Anyanwu/Sitzmann/Hetjens/Klüter/Wuchter 
Fig. 4. Comparison of complete blood count (CBC) values before leukapheresis and within 21 days after leukapheresis. Comparison of white blood cells (WBC; $10^{3} / \mu \mathrm{l}$ ), granulocytes (Granu; $\left.10^{3} / \mu \mathrm{l}\right)$, lymphocytes (Lympho; $10^{3} / \mu \mathrm{l}$ ), monocytes (Mono; $10^{3} / \mu \mathrm{l}$ ), red blood cells (RBC; $10^{6} / \mu \mathrm{l}$ ) and platelets (PLT; $10^{5} / \mu \mathrm{l}$ ). Blood samples were taken from all donors before leukapheresis (pre) and from donors who returned within 21 days (post). Box plots show median (line), 25th to 75 th percentile (box) and minimum to maximum values (whiskers) from 43 leukapheresis procedures; ${ }^{\dagger} \mathrm{p}<0.05 ;{ }^{\ddagger} \mathrm{p}<0.001$.

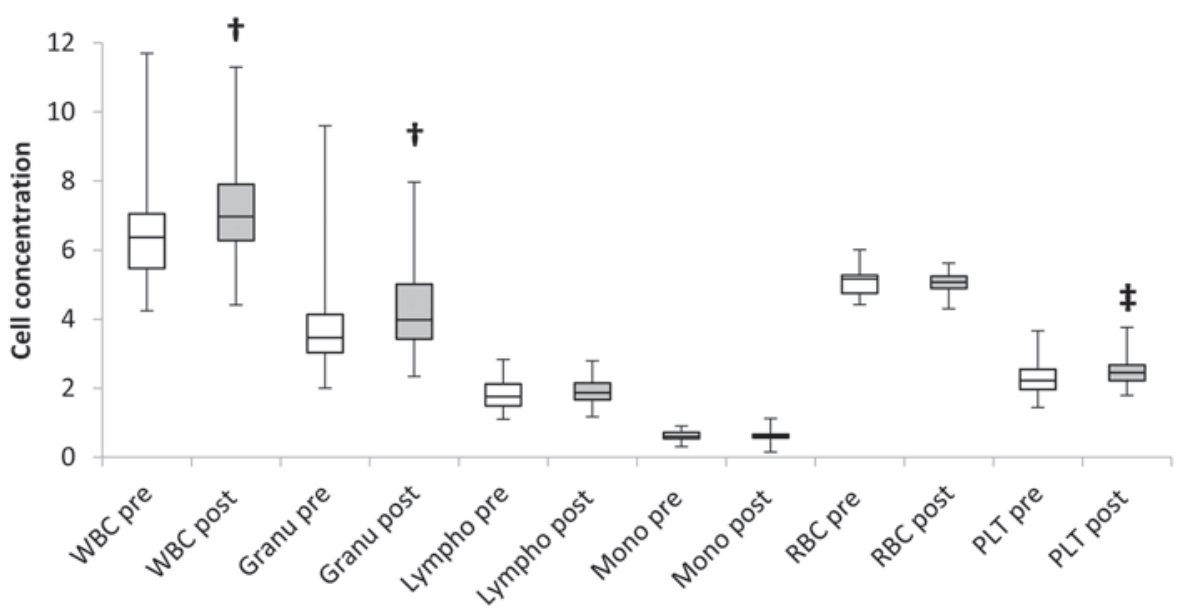

the correlation between pre-apheresis values and the corresponding cell yield. We were able to identify TPV as one additional variable influencing this correlation, but the TPV only influenced the results of lymphocytes and monocytes to a relevant measure.

Detecting the decrease in the post-apheresis CBC values, we sought to evaluate the cell loss and the presence of recruitment despite the low amount of the TBV which was processed in our study. We found negative values of the cell loss in all cell populations with variable frequency and in a variable number of leukapheresis procedures. These results generally suggested that recruitment had taken place in all cell populations and donors, but to varying degrees within each cell population. Taking the fluid balance into account, we demonstrated a perfect negative correlation between the cell loss and recruitment for all cell populations - the higher the recruitment the lesser the cell loss of the respective cell population in the CBC. Strasser et al. [18] demonstrated likewise an inverse correlation between the WBC or PLT loss and the WBC or PLT recruitment, respectively. But in contrast to our data, the perfect correlation of both variables could not be shown. Regarding the RF values, the values of Punzel et al. [10] for WBCs, MNCs, and lymphocytes were nearly twice as high when compared to our values. The same applies to the RF values for CD45+, CD3+ and CD14+ cells presented by Strasser et al. 2005 [15] and 2007 [18]. It is likely that all these diverse observations in cell loss and the RF may be due to the different calculation formulas used. Besides, we ensured that the differences we had observed in the $\mathrm{CBC}$ values before and after apheresis were not solely due to a dilution effect.

To assess the effect of cell loss and recruitment on the leukapheresis procedure and determine the variables influencing them, we correlated the cell loss and RF to the CE2 values for each cell population. But we only found a strong negative correlation between the cell loss and the CE2 values and a strong positive correlation between the RF and CE2 value for the lymphocytes. Punzel et al. [10] had concluded that the recruitment was regulated only by the cell concentration in the peripheral blood or by the number of cells removed during a leukapheresis procedure [10]. The correlations illustrated in figure 3 support this hypothesis for the lymphocytes, indicating the higher the CE2 value, the higher the recruitment of lymphocytes. On the other hand, the higher the CE2 value of lymphocytes, the lesser is their cell loss. As we could not observe these two correlations for any other cell population, we speculate that a certain threshold of the CE2 value may have to be exceeded before these two correlations become strong enough. Thus, we support the conclusion of Punzel et al. [10] that the recruitment is regulated only by the number of cells removed during a leukapheresis procedure.

Regarding the decrease in the $\mathrm{CBC}$ values immediately after leukapheresis, we could show that it only took a mean of 16 days for all cell populations to reach initial $\mathrm{CBC}$ values. In contrast, the results by Strasser et al. [15] differed from ours. In their study, healthy donors underwent four 10-liter leukapheresis procedures within 8 weeks. Up to 4 months, they found a decrease in the CD45+ and CD3+ cells in comparison to the values at the onset of the first apheresis. The differences observed may be due to the methodology, since we assessed our post-apheresis blood count values already after one 5-liter leukapheresis procedure. In addition, we could show that the values for granulocytes and PLTs increased significantly within a mean of 16 days. This finding might be the result of increased serum levels of hematopoietic growth factors, which were stimulated by the number of cells removed during the leukapheresis procedure. Several publications have reported that serum levels of thrombopoietin (TPO) were significantly increased up to 7 days after plateletpheresis [19-21]. Furthermore, Dettke et al. [19] detected a decline in serum TPO levels as PLT counts increased. Weisbach et al. [21], who focused on systemic levels of diverse hematopoietic growth factors, found likewise a significantly increased erythropoietin level after plateletpheresis, whereas the stem cell factor levels decreased significantly. They concluded that a coordinated response of the hematopoietic system occurring after platelet loss is responsible for this reaction. This could also apply to our leukapheresis procedures, since we found the highest percentage of cell recruitment in RBCs, granulocytes and PLTs with the aim to maintain or re-establish homeostatic order in non-cytokine-stimulated donors. Besides, the PLT loss in our leukapheresis procedures corresponds to a single-product plateletpheresis.

The CE2 value is surely one of many parameters which can be used to measure the outcome of an apheresis. Nevertheless, it is the 
most frequently calculated parameter in clinical practice given that it does not require a post-apheresis cell count and, in this respect, can be used to predict the cell yields in the collected product [22, 23]. Despite an inter-individual variation of the CE2 value, the duration of leukapheresis procedures can therefore easily be adapted to the cell amount required, which results in a higher donor safety. Accordingly, high predictable CE2 values of MNCs in combination with a high purity of MNC in the product are the desired outcomes of each leukapheresis.

\section{Conclusion}

Low-volume leukapheresis performed with the CMNC program of the Spectra Optia system resulted in a good product quality with high purity of MNCs and could be verified as a feasible method for the collection of MNCs. The CE2 value should be used to predict the desired cell yield in the product and adjust the operational settings accordingly to increase donor safety. In this respect, the Hct collected in the product is negligible for the collection efficiency, cell yield, or contamination of residual cells under operational settings recommended by the manufacturer. Regarding the donor re- sponse to leukapheresis, our data suggests that the cell recruitment during leukapheresis is regulated by the number of cells removed from the peripheral blood of the donor. Furthermore, the cell loss may also be the stimulus to induce granulo- and thrombopoiesis within the first days after leukapheresis via an increase in serum levels of hematopoietic growth factors. Taken together our findings imply that low volume leukapheresis can safely be repeated after 21 days without having to fear to compromise the donors $\mathrm{CBC}$ values.

\section{Acknowledgments}

The authors would like to thank Kirsten Welle and her team of operators for their help in performing the leukapheresis and the data acquisition.

\section{Disclosure Statement}

The first author and all co-authors confirm that there are no potential conflicts of interest to disclose, except the following: Patrick Wuchter - Membership in Advisory Boards for Sanofi-Aventis.

\section{References}

1 Strasser EF, Eckstein R: Optimization of leukocyte collection and monocyte isolation for dendritic cell culture. Transfus Med Rev 2010;24:130-139.

$\checkmark 2$ Bundesärztekammer: Richtlinie zur Gewinnung von Blut und Blutbestandteilen und zur Anwendung von Blutprodukten; in Richtlinien Hämotherapie. Cologne, Deutscher Ärzteverlag , 2017, p 115.

3 Nguyen XD, Eichler H, Sucker A, Hofmann U, Schadendorf D, Klüter H: Collection of autologous monocytes for dendritic cell vaccination therapy in metastatic melanoma patients. Transfusion 2002;42:428-432.

4 Strasser EF, Berger TG, Weisbach V, Zimmermann R, Ringwald J, Schuler-Thurner B, Zingsem J, Eckstein R: Comparison of two apheresis systems for the collection of cd14+ cells intended to be used in dendritic cell culture. Transfusion 2003;43:1309-1316.

5 Schulz M, Bialleck H, Thorausch K, Bug G, Dunzinger $\mathrm{U}$, Seifried E, Bonig H: Unstimulated leukapheresis in patients and donors: comparison of two apheresis systems. Transfusion 2014;54:1622-1629.

6 Cancelas JA, Scott EP, Bill JR: Continuous CD34+ cell collection by a new device is safe and more efficient than by a standard collection procedure: results of a two-center, crossover, randomized trial. Transfusion 2016;56:2824-2832.

7 Lisenko K, Pavel P, Bruckner T, Puthenparambil J, Hundemer M, Schmitt A, Witzens-Harig M, Ho AD, Wuchter P: Comparison between intermittent and continuous Spectra Optia leukapheresis systems for autologous peripheral blood stem cell collection. J Clin Apher 2017;32:27-34.

$\checkmark$ Pandey S, Cottler-Fox M: Optia ${ }^{\circledR}$ continuous mononuclear collection (CMNC) system is a safe and efficient system for hematopoietic progenitor cells-apheresis (HPC-A) collection and yields a lower product hematocrit (hct\%) than the Cobe ${ }^{\circledR}$ spectra system: a retrospective study. J Clin Apher 2018; doi: 10.1002/ jca. 21629 .
Sanderson F, Poullin P, Smith R, Nicolino-Brunet C, Philip P, Chaib A, Costello R: Peripheral blood stem cells collection on Spectra Optia apheresis system using the continuous mononuclear cell collection protocol: a single center report of 39 procedures. J Clin Apher 2017;32:182-190.

10 Punzel M, Kozlova A, Quade A, Schmidt AH, Smith R: Evolution of MNC and lymphocyte collection settings employing different Spectra Optia ${ }^{\circledR}$ leukapheresis systems. Vox Sang 2017;112:586-594.

11 Steininger PA, Strasser EF, Weiss D, Achenbach S, Zimmermann R, Eckstein R: First comparative evaluation of a new leukapheresis technology in non-cytokine-stimulated donors. Vox Sang 2014;106:248-255.

12 Strasser EF, Dittrich S, Weisbach V, Zimmermann R, Ringwald J, Achenbach S, Zingsem J, Eckstein R: Comparison of two mononuclear cell program settings on two apheresis devices intended to collect high yields of CD14+ and CD3+ cells. Transfusion 2004;44:11041111.

13 Steininger PA, Smith R, Geier C, Zimmermann R, Eckstein R, Strasser EF: Leukapheresis in non-cytokinestimulated donors with a new apheresis system: firsttime collection results and evaluation of subsequent cryopreservation. Transfusion 2013;53:747-756.

14 Jestice HK, Boraks P, Scott MA, Bloxham D, Price J, Marcus RE: Improved yield of peripheral blood progenitor cells on the Cobe Spectra. Bone Marrow Transplant 1996;18:597-601.

15 Strasser EF, Zimmermann R, Weisbach V, Ringwald J, Zingsem J, Eckstein R: Mononuclear cell variability and recruitment in non-cytokine-stimulated donors after serial 10-liter leukapheresis procedures. Transfusion 2005;45:445-452.

16 Knudsen LM, Nikolaisen K, Gaarsdal E, Johnsen HE: Kinetic studies during peripheral blood stem cell collection show CD34+ cell recruitment intra-apheresis. J Clin Apher 2001;16:114-119.
7 Svensson A, Adamson L, Pisa P, Petersson M, Hansson M: Monocyte enriched apheresis for preparation of dendritic cells (DC) to be used in cellular therapy. Transfus Apher Sci 2005;33:165-173.

18 Strasser EF, Schremmer M, Hendelmeier M, Weiss D, Ringwald J, Zimmermann R, Weisbach V, Zingsem J, Eckstein R: Automated CD14+ monocyte collection with the autoMNC program of the COM.TEC cell separator. Transfusion 2007;47:2297-2304.

19 Dettke M, Hlousek M, Kurz M, Leitner G, Rosskopf K, Stiegler G, Stohlawetz P, Worel N, Hocker P, Panzer S: Increase in endogenous thrombopoietin in healthy donors after automated plateletpheresis. Transfusion 1998;38:449-453.

20 Wagner T, Schwartz DW, Winter M, Kabrna E, Kollars M, Schwarzinger I, Lanzer G, Mayr WR, Geissler K: Kinetics of CFU-MK after automated plateletpheresis. Vox Sang 2001;81:167-171.

21 Weisbach V, Friedlein H, Glaser A, Zingsem J, Zimmermann R, Eckstein R: The influence of automated plateletpheresis on systemic levels of hematopoietic growth factors. Transfusion 1999;39:889-894.

22 Karafin MS, Graminske S, Erickson P, Walters MC, Scott EP, Carter S, Padmanabhan A: Evaluation of the Spectra Optia apheresis system for mononuclear cell (MNC) collection in G-CSF mobilized and nonmobilized healthy donors: results of a multicenter study. J Clin Apher 2014;29:273-280.

23 Wuchter P, Hundemer M, Schmitt A, Witzens-Harig M, Pavel P, Hillengass J, Goldschmidt $\mathrm{H}$, Ho AD, Lisenko K: Performance assessment and benchmarking of autologous peripheral blood stem cell collection with two different apheresis devices. Transfus Med 2017;27:36-42. 